\title{
The Basics Revisited: Nontextual approaches to teaching in information studies
}

\author{
Kiersten F. Latham ${ }^{\mathrm{a}, *}$ and Tim Gorichanaz ${ }^{\mathrm{b}}$

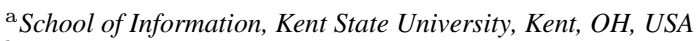 \\ ${ }^{\mathrm{b}}$ College of Computing and Informatics, Drexel University, Philadelphia, PA, USA
}

We humans have myriad modes of communication at our disposal. Even so, in academia we tend to limit ourselves to text, and we've done so for the past few hundred years. We write books, articles, reports and on the whiteboard; we ask students to write research papers, reports and journal reflections. Text, while undeniably useful, can be limiting. As Ferdinand de Saussure noted, writing has at once "usefulness, shortcomings, and dangers" [1]. We would also add that, for most of human existence, people have communicated (quite effectively!) without writing [2]. Recently, academics have begun exploring non-traditional research outputs, such as visual and performance arts, design work, curation, and more. Many challenges lie ahead for assessing the significance of such works when it comes to academic apparatuses like tenure and promotion, but progress is being made (particularly in Australia; see https://nitro.edu.au).

Though the road is uphill for scholarship, teaching beyond text is well within reach for departments, programs and individual instructors. In this special issue of Education for Information, we asked authors to explore the possibilities beyond textbased teaching in information studies education, building on a previous special issue on innovative pedagogies (volume 32, issue 1). With the papers in this issue, we see a return to learning and teaching with many of those tried-and-true methods storytelling, drawing, exhibition, kinesthetics and community.

This special issue opens with two short works describing teaching practice. In "Storytelling", McDowell discusses storytelling as a form of pedagogy. In particular, she details her MLIS course on Storytelling, which she has developed over the past 11 years. In "Writing without Words", Stoerger illustrates how her information technology students created infographics to express scholarly research and learning. Their work process involved analyzing and synthesizing complex information about a given topic in order to create a unique digital artifact, which could then be used as a portfolio piece.

\footnotetext{
*Corresponding author: Kiersten F. Latham, School of Information, Kent State University, Kent, OH, USA. E-mail: kflatham@kent.edu.
} 
The issue continues with two full papers that present two different approaches to using a draw-and-write technique to teach conceptual and theoretical topics. In "(i) Square Dancing", Hartel and Nguyen offer a strategy for instructors to guide students through learning and practicing visual data analysis with draw-and-write datasets. Their paper describes the process from start to finish, giving instructors a handy guide for implementing the technique in their own classes. Next, in "Combining an Arts-Informed and Textual Approach to Teaching Information and Communication Theories", Ibekwe-SanJuan demonstrates how the draw-and-write research technique can be adapted to teach theories in the information and communication sciences. Innovatively, her approach combines classic textual/verbal teaching with artsinformed pedagogy in the form of an exhibition, creative writing and storytelling.

In the next paper, "Holistic Competency Development and the Significance of Learning Domains in Audiovisual Archiving Education", Gracy discusses audiovisual archiving education and the as-yet missed opportunity for psychomotor teaching and learning in that domain. She expertly takes us through the history and brings to our attention the need for teaching "softer" skills, those using the hands and other senses. Finally, in "Going Beyond the Text", Freeburg helps us turn the classroom into a community of practice by moving beyond the established canon. In the noncanonical approach he describes, students are invited to participate in the creation and development of new knowledge in their field. More than just a technique, Freeburg's approach challenges our current ideas of the roles of students and instructors, showing how to strategically put students in positions of leadership and allow them to become agents of change.

This collection of papers serves as an inspiring entrée to non-text-based instruction in our field. Where will this lead us? As we begin to imagine the future, we find it helpful to reflect on the openings that these papers spark:

- Many of the papers in this issue focused on visual, non-verbal information. What about the other senses? Gracy brings psychomotor activities to the fore, but what about listening and smell? What other senses have untapped learning potential?

- All of these papers discuss learning in face-to-face environments. Still, more and more of us find ourselves teaching online. How can non-textual techniques, methods and approaches be harnessed in online environments?

- With the exception of one paper describing learning in France, all of the papers in this issue describe North American classrooms. What else can we learn from teaching in other parts of the world?

- The papers in this issue richly describe teaching in situ, but do not point to the evidence of the effectiveness of these techniques in the long term. As we continue to explore and advocate for non-textual teaching, how can we be sure to gather such evidence?

- Finally, and perhaps surprisingly, very little in this issue describes working with new technologies. On the contrary, we seem to be going back to the basics: storytelling, drawing, moving, showing and talking face-to-face. How can these 
ancient ways of learning be fruitfully married with new technologies? Should they?

We also looked back at our call for papers, and we would like to point out a few areas in which we saw no submissions. These would seem to be sites for future research and development:

- Explorations of practice-led and productive teaching methods - and beyond!

- Perspectives of not just instructors, but also learners, administrators, staff and other stakeholders

- Intersections between course content and other department/institution offerings (reading groups, research centers, seminar series, organizations, institutes and more)

So much for our reflections. Now we ask you: What is missing? What questions should we be asking? What non-textual approaches to teaching and learning are in our future?

\section{References}

[1] De Saussure, F. Course in general linguistics. New York: Philosophical Library; 1959.

[2] Ong, WJ. Orality and literacy: the technologizing of the word. London: Routledge; 2001. 